\title{
As metodologias ativas e a promoção da autonomia de estudantes
}

\section{Active methodologies and the nurturing of students' autonomy}

\author{
Neusi Aparecida Navas Berbel ${ }^{1}$
}

\begin{abstract}
Resumo
Com este artigo, registra-se uma reflexão respaldada na literatura, tomando como interface estudos voltados para a promoção da autonomia de alunos e o potencial da área pedagógica, com o uso de metodologias ativas, para a obtenção de resultados na mesma direção. O objetivo maior da elaboração do texto é o de, ao identificar pontos de convergência entre essas duas linhas de estudos, compartilhá-los com educadores e seus formadores, provocando uma reflexão crítica e possíveis experimentos, no sentido de ampliar registros e discussões com vistas à qualidade do ensino. São exemplificadas alternativas metodológicas com suas características essenciais, com ênfase na metodologia da problematização com o arco de Maguerez, pelo potencial de levar alunos a aprendizagens para a autonomia, assim como estudos que a utilizaram.

Palavras chave: Metodologias ativas. Promoção da autonomia. Metodologia da problematização.
\end{abstract}

\begin{abstract}
In this article, a literature-based reflection is registered, taking studies aimed at the nurturing of students' autonomy and the potential of the pedagogic area with active methodologies as interface to achieve results in the same direction. The main objective of the text is to identify converging points between these two study areas and share them with educators and their professors, inciting critical thinking and possible experiments in order to increase the amount of data as well as discussions about the quality of teaching. Methodological alternatives are exemplified in their essential characteristics, emphasizing the problematization methodology within Maguerez's Arch to guide students to autonomy learning as well as the studies that have been used.
\end{abstract}

Keywords: Active methodologies. Autonomy nurturing. Problematization methodology.

\section{Introdução}

É recorrente entre, os estudiosos de Educação das últimas décadas, a ideia de que já não bastam informações para que crianças, jovens e adultos possam, com a contribuição da escola, participar de modo integrado e efetivo da vida em sociedade. Embora imprescindíveis, as informações em si teriam, quando apenas retidas ou memorizadas, um componente de reprodução, de manutenção do já existente, colocando os aprendizes na condição de expectadores do mundo.

A complexidade crescente dos diversos setores da vida no âmbito mundial, nacional e local tem demandado o desenvolvimento de capacidades humanas de pensar, sentir e agir de modo cada vez mais amplo e profundo, comprometido com as

\footnotetext{
1 Doutora em Educação pela Faculdade de Educação da USP. Docente do Departamento de Educação - CECA da Universidade Estadual de Londrina (UEL). Área de Didática. Email: berbel@uel.br
} 
questões do entorno em que se vive.

Faz parte das funções da escola contribuir para que tal desenvolvimento ocorra. A legislação nacional da educação sinaliza para isso de diferentes modos, de acordo com os diferentes níveis de escolaridade. Por exemplo, para o ensino fundamental, prevê como objetivo, o desenvolvimento da capacidade de aprendizagem, tendo em vista a aquisição de conhecimentos e habilidades e a formação de atitudes e valores (BRASIL, 1996). Para o ensino médio, entre outros objetivos, no Art. 35, em seu inciso III, prevê-se o aprimoramento do educando como pessoa humana, incluindo a formação ética e o desenvolvimento da autonomia intelectual e do pensamento crítico. No Art. 43, lemos que a educação superior tem por finalidade: I - estimular a criação cultural e o desenvolvimento do espírito científico e do pensamento reflexivo (BRASIL, 1996).

Portanto, juntamente com os diferentes tipos de informações a serem adquiridas, podemos compreender, pelos textos da Lei, que a escola tem a incumbência de atuar para promover o desenvolvimento humano, a conquista de níveis complexos de pensamento e de comprometimento em suas ações.

$\mathrm{Na}$ escola, o professor é o grande intermediador desse trabalho, e ele tanto pode contribuir para a promoção de autonomia dos alunos como para a manutenção de comportamentos de controle sobre os mesmos. Encontramos para a palavra Autonomia (2010), no dicionário Michaelis, os seguintes significados: "1 Qualidade ou estado de autônomo. 2 Sociol e Polit Autodeterminação político-administrativa de que podem gozar, relativamente, grupos (partidos, sindicatos, corporações, cooperativas etc.), em relação ao país ou comunidade política dos quais fazem parte. 3 Liberdade moral ou intelectual". Embora ligado à área da sociologia e da política, esse dicionário apresenta o termo autodeterminação, que é utilizado pela psicologia de modo associado com os conceitos de motivação e autonomia.

Com outras palavras, mas na mesma direção, no Novo Dicionário da Língua Portuguesa(HOLANDA, 1986), autonomia significa a faculdade de se governar por si mesmo; o direito ou faculdade de se reger por leis próprias; liberdade ou independência moral ou intelectual. Esse conceito se apresenta tendo como foco uma nação, mas diferentes áreas da atividade humana dele se apropriam. Guimarães (2003, p. 36) se utiliza dessa conceituação para explicar que "o adjetivo autônomo refere-se a agir sem controle externo e o termo autodeterminação lhe é associado de modo bastante apropriado". Explica, ainda, que "para a teoria da autodeterminação, o conceito de autonomia é vinculado ao desejo ou à vontade de o organismo organizar a experiência e o próprio comportamento e para integrá-los ao sentido do self" (GUIMARÃES, 2003, p. 36).

Segundo Guimarães (2003), a ideia da necessidade psicológica básica de autodeterminação ou autonomia foi inspirada no trabalho de DeCharms (1984), que destacou a autodeterminação como uma necessidade humana inata, relacionada à motivação intrínseca. A autora reforça o pensamento segundo o qual os indivíduos são naturalmente propensos a realizar uma atividade por acreditarem que o fazem por vontade própria, porque assim o desejam e não por serem obrigados por força de demandas externas. Agem de forma intencional com o objetivo de produzir alguma mudança. Com essas características, esses indivíduos são denominados de "origem" ou se considera que eles têm o locus de causalidade interno.

Desse modo, os hábitos são aprendidos para serem utilizados na ação e os conhecimentos são aprendidos para guiar a ação. "Quando ambos, hábitos e conhecimentos, combinados com a motivação, são satisfatórios, o sujeito percebe que foi ele quem causou a mudança desejada" (GUIMARÃES, 2003, p. 38). Em decorrência dessa percepção, seus comportamentos podem ser intrinsecamente motivados, fixando metas 
pessoais, demonstrando seus acertos e dificuldades, planejando as ações necessárias para viabilizar seus objetivos e avaliando adequadamente seu progresso, como explica a autora.

De outro modo, vamos encontrar os que se percebem como "marionetes", apresentando sentimentos negativos por serem externamente guiados, tendo as causas de seus comportamentos relacionadas a fatores externos, como o comportamento ou a pressão de outras pessoas. Essa situação promove sentimentos de fraqueza e ineficácia, implica o afastamento de situações de desempenho e acarreta o desenvolvimento precário das habilidades que possibilitariam uma melhor interação com eventos do ambiente, explica Guimarães (2003). Ao sentir-se obrigado a realizar algo por fatores externos, o indivíduo tem sua atenção desviada da tarefa, diminuindo as possibilidades de manifestar-se a motivação intrínseca.

São de DeCharms (1968 apud GUIMARÃES, 2003, p. 39), as seguintes palavras: “As pessoas extrinsecamente motivadas sentem-se frequentemente como marionetes da autoridade ou das recompensas, mas as pessoas intrinsecamente motivadas sentem-se como origem, comportandose com liberdade e auto-investimento [...]". A partir desse entendimento, Guimarães (2003) ressalta que o locus de causalidade é uma característica que pode se alterar na vida do indivíduo, sendo este identificado como de origem ou com influência acentuadamente externa (marionete) ou ainda em um nível intermediário entre essas duas posições, dependendo da situação, que pode se configurar como mais facilitadora da experiência de ser origem ou marionete ou estar situado entre as duas experiências.

A importância de se pensar nas diferenças de locus de causalidade, no âmbito da teoria da autodeterminação, justifica-se porque tal oscilação possibilitou a compreensão de resultados de pesquisas que demonstram que as recompensas externas apresentam-se como prejudiciais para a motivação intrínseca, influenciando a experiência pessoal de autonomia. Em outras palavras, as recompensas externas acarretam "um impacto significativo na motivação e na qualidade do desempenho, diminuindo a motivação intrínseca, a criatividade e a capacidade de resolução de problemas", como lemos em Guimarães (2003, p. 39). Outros estudos em laboratório, em situações escolares reais e em organizações de trabalho têm demonstrado resultados positivos naquelas situações que promovem a autonomia, comparadas a situações controladoras.

Deci e Ryan (2000 apud GUIMARÃES, 2003) consideram que seria inconcebível imaginar que houvesse alguma situação em nossa vida cotidiana na qual pudéssemos agir de modo totalmente independente das influências externas. E Guimarães (2003, p. 40) afirma:

\begin{abstract}
O cerne da questão está no fato da pessoa contribuir com as forças que influenciam suas ações, ou seja, se ela permanece de modo passivo diante das demandas externas, um "marionete" na concepção de deCharms (1984), as aceita, compreende-as por seu valor e utilidade ou as percebe como fonte de informações que servem de apoio para as suas iniciativas. [...] Em suma, autonomia aqui significa autogoverno, autodireção, autodeterminação.
\end{abstract}

Concorrem para a promoção da autonomia as atividades de aprendizagem que possibilitam, por exemplo, conforme Bzuneck e Guimarães (2010), que, em relação a um dado comportamento, haja envolvimento pessoal, baixa pressão e alta flexibilidade em sua execução, e percepção de liberdade psicológica e de escolha. Por outro lado, o controle caracteriza-se por uma regulação externa, ou seja, a pessoa age em função de eventos externos como pressões e obrigações, prazos fatais, recompensas, punições e ameaças. No ambiente escolar, a competição e as notas são percebidas como poderosas fontes de controle, conforme estudos mencionados pelos autores. Estes autores, ao tratarem da promoção da autonomia como estratégia motivacional na escola, dão destaque ao clássico estudo de Reeve, Bolt e Cai (1999 apud BZUNECK; 
GUIMARÃES, 2010), que identificaram os estilos motivacionais de estudantes de um curso de formação de professores. Nesse estudo, os participantes, caracterizados como promotores de autonomia, diferentemente dos que primavam por utilizar técnicas de controle, relataram adotar os seguintes comportamentos em suas interações com os alunos: (a) ouvem-nos com mais frequência; (b) permitem que eles lidem de modo pessoal com materiais e idéias; (c) perguntam o que seus alunos querem; (d) respondem aos questionamentos; (e) assumem com empatia o ponto de vista deles; (f) com menor probabilidade dão soluções; (g) tendem mais a centralizar-se nos alunos, com encorajamento de iniciativas e com comunicações não controladoras.

Em estudo mais recente de Reeve (2009), o autor enfatiza que alunos que se percebem autônomos em suas interações escolares apresentam resultados positivos em relação: 1- à motivação (apresentando motivação intrínseca, a percepção de competência, pertencimento, curiosidade, internalização de valores); 2- ao engajamento (com emoções positivas, persistência, presença nas aulas, não reprovam ou se evadem da escola); 3- ao desenvolvimento (evidenciando autoestima, autovalor, preferência por desafios ótimos, criatividade); 4- à aprendizagem (melhor entendimento conceitual, processamento profundo de informações, uso de estratégias autorreguladas); 5- à melhoria do desempenho em notas, nas atividades, nos resultados em testes padronizados); e 6- ao estado psicológico (apresentando indicadores de bem-estar, satisfação com a vida, vitalidade).

O mesmo autor apresenta algumas pistas para que os professores estabeleçam as condições básicas para o surgimento do estilo motivacional que promova a autonomia. O professor deve adotar a perspectiva do aluno, deve acolher seus pensamentos, sentimentos e ações, sempre que manifestados, e apoiar o seu desenvolvimento motivacional e capacidade para autorregular-se.
Nesse sentido, o professor contribui para promover a autonomia do aluno em sala de aula, quando: a) nutre os recursos motivacionais internos (interesses pessoais); b) oferece explicações racionais para o estudo de determinado conteúdo ou para a realização de determinada atividade; c) usa de linguagem informacional, não controladora; d) é paciente com o ritmo de aprendizagem dos alunos; e) reconhece e aceita as expressões de sentimentos negativos dos alunos (REEVE, 2009).

Parece-nos que essess comportamentos de professores seriam os requeridos daqueles que buscam conduzir a formação de futuros profissionais nas mais diversas áreas, e que pode ser estimulada por meio de metodologias ativas. A implementação dessas metodologias pode vir a favorecer uma motivação autônoma quando incluir o fortalecimento da percepção do aluno de ser origem da própria ação, ao serem apresentadas oportunidades de problematização de situações envolvidas na programação escolar, de escolha de aspectos dos conteúdos de estudo, de caminhos possíveis para o desenvolvimento de respostas ou soluções para os problemas que se apresentam alternativas criativas para a conclusão do estudo ou da pesquisa, entre outras possibilidades.

As metodologias ativas têm o potencial de despertar a curiosidade, à medida que os alunos se inserem na teorização e trazem elementos novos, ainda não considerados nas aulas ou na própria perspectiva do professor. Quando acatadas e analisadas as contribuições dos alunos, valorizandoas, são estimulados os sentimentos de engajamento, percepção de competência e de pertencimento, além da persistência nos estudos, entre outras. Com a intenção de fazer a aproximação entre estes estudos voltados para a promoção da autonomia do aluno e o potencial da área pedagógica na mesma direção, trazemos a seguir alguns aspectos relacionados e algumas características das Metodologias Ativas. 


\section{As Metodologias Ativas - Um Entendimento Inicial}

Para a elaboração de novas propostas pedagógicas, os cursos de graduação e com destaque os da área da saúde, têm sido estimulados a incluírem, em suas reorganizações, metodologias de ensino que permitam dar conta dos novos perfis delineados para os seus profissionais.

Como um exemplo, no Inciso I do Art. $3^{\circ}$ da Resolução CNE/CES 3/2001, que Institui Diretrizes Curriculares Nacionais do Curso de Graduação em Enfermagem, percebemos características orientadoras da formação para um profissional generalista, humanista, crítico e reflexivo; qualificado para o exercício da profissão com base no rigor científico e intelectual e pautado em princípios éticos; que seja capaz de conhecer e intervir sobre os problemas/situações de saúdedoença mais prevalentes no perfil epidemiológico nacional, com ênfase na sua região de atuação, identificando as dimensões bio-psico-sociais dos seus determinantes; que esteja capacitado a atuar, com senso de responsabilidade social e compromisso com a cidadania, como promotor da saúde integral do ser humano.

Entre outras capacidades, esse profissional deverá estar apto, portanto, à resolução de problemas de saúde, tanto em nível individual como coletivo; a tomar decisões apropriadas; ao exercício da liderança, da administração e do gerenciamento (CONSELHO NACIONAL DE EDUCAÇÃO, 2001).

Face a perfis profissionais como esse, as Instituições de Ensino Superior têm lançado mão do que convencionou-se denominar de Metodologias Ativas. Encontramos em Paulo Freire (1996) uma defesa para as metodologias ativas, com sua afirmação de que na educação de adultos, o que impulsiona a aprendizagem é a superação de desafios, a resolução de problemas e a construção do conhecimento novo a partir de conhecimentos e experiências prévias dos indivíduos.
Bastos (2006) nos apresenta uma conceituação de Metodologias Ativas como "processos interativos de conhecimento, análise, estudos, pesquisas e decisões individuais ou coletivas, com a finalidade de encontrar soluções para um problema." Nesse caminho, o professor atua como facilitador ou orientador para que o estudante faça pesquisas, reflita e decida por ele mesmo, o que fazer para atingir os objetivos estabelecidos. Segundo o autor, trata-se de um processo que oferece meios para que se possa desenvolver a capacidade de análise de situações com ênfase nas condições loco-regionais e apresentar soluções em consonância com o perfil psicossocial da comunidade na qual se está inserido.

Podemos entender que as Metodologias Ativas baseiam-se em formas de desenvolver o processo de aprender, utilizando experiências reais ou simuladas, visando às condições de solucionar, com sucesso, desafios advindos das atividades essenciais da prática social, em diferentes contextos.

Mitri et al. (2008) explicam que as metodologias ativas utilizam a problematização como estratégia de ensino/aprendizagem, com o objetivo de alcançar e motivar o discente, pois diante do problema, ele se detém, examina, reflete, relaciona a sua história e passa a ressignificar suas descobertas. Segundo os autores, a problematização pode levar o aluno ao contato com as informações e à produção do conhecimento, principalmente, com a finalidade de solucionar os impasses e promover o seu próprio desenvolvimento. Aprender por meio da problematização e/ou da resolução de problemas de sua área, portanto, é uma das possibilidades de envolvimento ativo dos alunos em seu próprio processo de formação.

$\mathrm{O}$ engajamento do aluno em relação a novas aprendizagens, pela compreensão, pela escolha e pelo interesse, é condição essencial para ampliar suas possibilidades de exercitar a liberdade e a autonomia na tomada de decisões em diferentes momentos do processo que vivencia, preparandose para o exercício profissional futuro. Para isso, 
deverá contar com uma postura pedagógica de seus professores com características diferenciadas daquelas de controle.

Essa nova ênfase que vem sendo dada ao ensino para levar a aprender a partir de problemas ou situações problemáticas, nas duas últimas décadas, encontra parte de suas bases em um momento histórico já bem distante, com Dewey (1859-1952), filósofo, psicólogo e pedagogo norte-americano, que teve grande influência sobre a pedagogia contemporânea. Ele formulou um ideal pedagógico (da Escola Nova) de que a aprendizagem ocorresse pela ação - learning by doing - ou o aprender fazendo.

Gadotti (2001, p. 148), em sua História das Pedagogias, conta que Dewey "praticou uma crítica contundente à obediência e submissão até então cultivadas nas escolas", que seriam verdadeiros obstáculos à educação. Para superar essas posturas, defendia os princípios da iniciativa, da originalidade e da cooperação para liberar as potencialidades dos indivíduos para uma ordem social a ser progressivamente aperfeiçoada. A realização dos princípios da Escola Nova demandava métodos ativos e criativos, centrados no aluno e essa foi uma grande contribuição desse movimento da educação, que se fortaleceu por meio de seus seguidores.

"Para John Dewey, a experiência concreta da vida se apresentava sempre diante de problemas que a educação poderia ajudar a resolver." (GADOTTI, 2001, p. 143). O pedagogo explicava que o ato de pensar mobilizado diante de um problema, passaria por cinco estágios: $1^{\circ}$ - uma necessidade sentida; $2^{\circ}$ - a análise da dificuldade; $3^{\circ}$ - as alternativas de solução do problema; $4^{\circ}$ - a experimentação de várias soluções, até que o teste mental aprove uma delas; $5^{\circ}$ - a ação como a prova final para a solução proposta, que deve ser verificada de maneira científica (GADOTTI, 2001, p. 143144). Percebemos hoje que esses estágios viriam a ser apropriados e adaptados depois, por outros educadores, em suas propostas, como podemos constatar pelo que apresentamos na sequência.

A história é dinâmica e outras concepções pedagógicas se apresentaram como alternativas à Escola Nova, mesmo não podendo negar a influência dela recebida em relação aos métodos ativos. Por exemplo, Paulo Freire (1921-1997) viria a estimular o desenvolvimento de uma Pedagogia Problematizadora, sustentada por uma concepção defendida por Gadotti como dialética, em que "educador e educando aprendem juntos, numa relação dinâmica na qual a prática, orientada pela teoria, reorienta essa teoria, num processo de constante aperfeiçoamento" (GADOTTI, 2001, p. 253).

Gadotti (2001) salienta duas grandes contribuições de Paulo Freire para o pensamento pedagógico brasileiro no século XX. Uma delas é a contribuição à teoria dialética do conhecimento, para a qual "a melhor maneira de refletir é pensar a prática e retornar a ela para transformá-la”. Freire sugere pensar o concreto, a realidade, e não pensar pensamentos. A outra é a categoria pedagógica da conscientização, visando, por meio da educação, "à formação da autonomia intelectual do cidadão para intervir sobre a realidade" (GADOTTI, 2001, p. 253-254). A educação, para Freire, não é neutra, mas sempre um ato político.

Educar para a autonomia significa também, consequentemente, um ato político e para o campo de formação profissional e ou formação de professores, um ato político pedagógico.

\section{Algumas Possibilidades de Metodologias Ativas}

São muitas as possibilidades de Metodologias Ativas, com potencial de levar os alunos a aprendizagens para a autonomia. O estudo de caso é uma delas, bastante utilizado em cursos de Direito, Administração, Medicina entre outros. Com o Estudo de Caso, o aluno é levado à análise de problemas e tomada de decisões. Conforme Abreu e 
Masetto (1985, p. 69), "o caso pode ser real, fictício ou adaptado da realidade". Os alunos empregam conceitos já estudados para a análise e conclusões em relação ao caso. Pode ser utilizado antes de um estudo teórico de um tema, com a finalidade de estimular os alunos para o estudo. O estudo de caso é recomendado para possibilitar aos alunos um contato com situações que podem ser encontradas na profissão e habituá-los a analisá-las em seus diferentes ângulos antes de tomar uma decisão.

O processo do incidente é uma variação do estudo de caso. Sua caracterização é extraída da descrição de Gil (1990, p. 84):

O professor apresenta à classe uma ocorrência ou incidente de forma resumida, sem oferecer maiores detalhes. A seguir, coloca-se à disposição dos alunos para fornecer-lhes os esclarecimentos que desejarem. Finda a sessão de perguntas, a classe é subdividida em pequenos grupos e os alunos passam a estudar a situação, em busca de explicações ou soluções.

Os grupos expõem as conclusões para a classe, estas são colocadas no quadro de giz e por último são debatidas pela classe toda. Segundo Gil (1990), esta técnica serve para alertar os alunos sobre a necessidade de maior número de informações quando se quer analisar fatos não presenciados. Por outro lado, requer mais preparo do professor, assim como de materiais relacionados.

Após a utilização do processo do incidente algumas vezes pelo professor, pensamos que os alunos podem ser orientados/convidados a preparar situações para desenvolvê-lo em sala com seus colegas, sob a supervisão do professor. Desse modo, a criatividade e a responsabilidade são estimuladas e valorizadas, podendo resultar no desenvolvimento de graus de envolvimento, de iniciativa, autoconfiança, ingredientes importantes para a autonomia.

O método de projetos é uma modalidade que pode associar atividades de ensino, pesquisa e extensão. Gradativamente, os projetos vão sendo incorporados na Escola Básica, no desenvolvimento de estudos dos Temas Transversais, em cursos de formação técnica e outros. Para Bordenave e Pereira
(1982, p. 233), “o método de projetos tem como principal objetivo lutar contra a artificialidade da escola e aproximá-la o mais possível da realidade da vida". Por meio desse método, afirmam os autores (BORDENAVE; PEREIRA, 1982, p. 233), o aluno "busca informações, lê, conversa, anota dados, calcula, elabora gráficos, reúne o necessário e, por fim, converte tudo isso em ponto de partida para o exercício ou aplicação na vida”. Nesse caso, os conteúdos escolares transformam-se em meios para a resolução de um problema da vida, e para a realização de um projeto. Em síntese, os projetos:

[...] são atividades que redundam na produção, pelos alunos, de um relatório final que sintetize dados originais (práticos ou teóricos), colhidos por eles, no decurso de experiências, inquéritos ou entrevistas com especialistas. O projeto deve visar à solução de um problema que serve de título ao projeto (BORDENAVE; PEREIRA, 1982, p. 233).

O projeto passa, segundo os autores, por quatro fases distintas: $1^{\mathrm{a}}-a$ intenção - curiosidade e desejo de resolver uma situação concreta, já que o projeto nasce de situações vividas; $2^{\mathrm{a}}-a$ preparação - estudo e busca dos meios necessários para a solução, pois não bastam os conhecimentos já possuídos; $3^{\mathrm{a}}$ - execução - aplicação dos meios de trabalho escolhidos, em que cada aluno busca em uma fonte as informações necessárias ao grupo; $4^{\mathrm{a}}$ - apreciação - avaliação do trabalho realizado, em relação aos objetivos finais. Afinal, a literatura, as informações do professor e os dados da realidade confirmam as hipóteses do projeto? Que outros subprojetos podem surgir do mesmo?

Emprestamos dos autores as palavras de Dewey, para aprendermos a reconhecer quando se trata ou não de um bom projeto: "Um projeto prova ser bom se for suficientemente completo para exigir uma variedade de respostas de diferentes alunos e permitir a cada um trazer uma contribuição que lhe seja própria e característica". Há ainda outra pista para essa mesma identificação: "que haja suficiente tempo para que se inclua uma série de trabalhos e explorações [...] que suscite novas 
dúvidas e questões, desperte a exigência de mais conhecimento e que sugira o que se deva fazer com base no conhecimento adquirido" (DEWEY apud BORDENAVE; PEREIRA, 1982, p. 234-235).

Entre as diversas contribuições aos alunos pela vivência do método de projetos, quando bem conduzido pelo(s) professor(es), podemos mencionar, a partir de Bordenave; Pereira (1982), os seguintes: proporcionar conteúdo vivo ao processo de aprendizagem; seguir o princípio da ação organizada em torno de objetivos; possibilitar a aprendizagem real, significativa, ativa, interessante, atrativa; concentrar na aprendizagem do aprendiz; desenvolver o pensamento divergente e despertar o desejo de conquista, iniciativa, investigação, criação e responsabilidade; levar os alunos a se inserirem conscientemente na vida social e/ou profissional. Podemos perceber, portanto, vários indicadores comuns entre os estudos voltados para a promoção da autonomia do aluno e o método ativo de projetos. Outros autores têm contribuído para a exploração desse método, entre os quais citamos Gandin (1983) e Hernándes e Ventura (1998).

A pesquisa cientifica também é uma modalidade de atividade bastante estimulada junto aos alunos do ensino superior, que a podem desenvolver como uma Iniciação Científica - I.C., em Trabalhos de Conclusão de Curso - TCC, inserindo-se como colaboradores em projetos de professores, entre outras possibilidades. Trata-se de importante atividade que permite aos alunos ascenderem do senso comum a conhecimentos elaborados, desenvolvendo, no caminho, habilidades intelectuais de diferentes níveis de complexidade, tais como a observação, a descrição, a análise, a argumentação, a síntese, além de desempenhos mais técnicos, como o de elaboração de instrumentos para coletar informações, tratá-las, ilustrá-la. Essas habilidades intelectuais, quando desenvolvidas, permitem aos alunos condições mais propícias de novas iniciativas, de maior segurança em tomadas de decisão e, consequentemente, a percepção dos alunos de que eles podem causar as mudanças desejadas, o que Guimarães (2003) associa com a possibilidade de comportamentos intrinsecamente motivados, ao fixarem metas pessoais, demonstrarem acertos e dificuldades, planejarem as ações necessárias para viabilizar seus objetivos e avaliarem adequadamente seu progresso.

A aprendizagem baseada em problemas (também conhecida pela sigla PBL, iniciais do termo em inglês Problem Based Learning) é outra modalidade inserida no conjunto das metodologias ativas, foi inicialmente introduzida no Brasil em currículos de Medicina, mas vem sendo experimentada também por outros cursos. Esta alternativa diferencia-se das demais antes apontadas, por constituir-se como o eixo principal do aprendizado técnico-científico numa proposta curricular. Conforme Sakai e Lima (1996), ela se desenvolve com base na resolução de problemas propostos, com a finalidade de que o aluno estude e aprenda determinados conteúdos. Segundo os autores, esta metodologia é formativa à medida que estimula uma atitude ativa do aluno em busca do conhecimento.

Encontramos, no site do Colegiado do curso de Medicina da Universidade Estadual de Londrina (UNIVERSIDADE ESTADUAL DE LONDRINA, 2005), uma descrição, que aqui sintetizamos: prepara-se um elenco de situações que o aluno deverá saber/dominar para o exercício de sua profissão. A análise das situações leva os especialistas a determinarem quais conhecimentos são necessários adquirir para cada uma delas, constituindo os temas de estudo. Cada tema relativo à esfera cognitiva é transformado em um problema para ser estudado e discutido pelos alunos no grupo tutorial. A esfera cognitiva do PBL deve garantir que o aluno estude situações suficientes para se capacitar a procurar o conhecimento por si mesmo quando se deparar com uma situação problema ou um caso clínico. Encontram-se muitos trabalhos explicativos do PBL e de suas aplicações, em artigos de periódicos e nos sites dos cursos de Medicina do país. 
A metodologia da problematização com o arco de Maguerez é mais uma alternativa metodológica nesse conjunto de Metodologias Ativas. Trabalhos com o arco de Maguerez têm sido realizados em ciências agrárias, em ciências da saúde, mas também em outros cursos. Com a designação de Metodologia da Problematização com o Arco de Maguerez, tem sido utilizada em estágios, no desenvolvimento de Iniciação Científica -I.C.- e de Trabalhos de Conclusão de Curso -TCC- no curso de Pedagogia, assim como em disciplina e na orientação de dissertações no Programa de Mestrado em Educação da UEL.

Descrevemos a seguir, com mais detalhes, aspectos da Metodologia da Problematização com o Arco de Maguerez, a partir de trabalhos realizados na UEL desde 1992. O arco de Maguerez, apresentado inicialmente por Bordenave e Pereira (1982), possui cinco etapas: observação da realidade e definição de um problema, pontos-chave, teorização, hipóteses de solução e aplicação à realidade. Várias descrições de suas características e aplicações realizadas em diferentes níveis de ensino, com diferentes temáticas e em diferentes tipos de pesquisa já estão disponibilizadas. Entre elas salientamos o texto "A Metodologia da Problematização com o Arco de Maguerez e sua relação com os saberes de professores", de Colombo; Berbel (2007), em que, entre outros aspectos, são pormenorizadas as ações a serem desenvolvidas pelos participantes de sua aplicação, em cada uma de suas etapas.

No desenvolvimento do processo, é necessário garantir algumas características como as descritas a seguir e, consequentemente, conquistar resultados desejados na direção da autonomia dos alunos.

- Os alunos é que problematizam a parcela da realidade associada ao foco do estudo, selecionam um dos problemas para estudar e buscam uma resposta ou uma solução para ele. Neste aspecto, cabe ao professor estimular esse novo aprendizado a seus alunos, já que a tradição maior é a de professores apresentarem os problemas para os alunos resolverem.
- Considera-se a realidade concreta para aprender com ela e para nela intervir, em busca de soluções para seus problemas. Conduzir os alunos a problematizarem aspectos da realidade viva, relacionado-os com temas de estudo é um fato pedagógico inegavelmente mais rico, quando comparado às atividades de estudo de grande parte dos programas escolares, tradicionalmente tratados como temas abstratos e distantes da vida dos estudantes.

- $\quad$ A participação do aluno se dá no exercício do aprender fazendo. Ao professor, cabe conduzir o processo metodologicamente, estimular as atividades dos alunos, apoiar e valorizar as iniciativas na direção do foco maior que é a solução ao problema em estudo. Nesse sentido, a cada etapa, realizam-se aprendizagens de várias ordens, como as de construção de instrumentos de busca de informações, tratamento das informações colhidas, análise, tomada de decisão, síntese, registros sistemáticos etc.

- A relação teoria-prática é constante. Mais que isso, ocorre, nesse percurso, uma dinâmica de ação-reflexão-ação, caracterizando-se esta última como uma ação transformadora, em algum grau. Nesse sentido, o percurso é percebido como uma forma de exercitar a práxis, entendida como uma prática consciente, refletida, informada e intencionalmente transformadora (BERBEL, 1996).

- A vivência desse caminho metodológico pelos alunos permite-lhes a construção de conhecimentos, pelo seu envolvimento com os dados da realidade e com as atividades de elaboração dos mesmos em cada etapa do processo.

- O processo se completa com algum grau de intervenção. Após a teorização dos pontos-chave definidos pelos participantes, seguem duas outras etapas bastante diferenciadoras desta metodologia em relação a outros processos pedagógicos mais usuais nas escolas em geral e nas universidades. São elaboradas criativamente hipóteses de solução e, dentre elas, serão escolhidas aquelas que serão 
colocadas em prática na parcela da realidade da qual se extraiu o problema de estudo. Desse modo, todo o estudo ganha sentido, já que servirá de fundamentação/sustentação para uma ação prática concreta na realidade.

- O fato de os alunos, desde o início, analisarem criticamente uma parcela da realidade para problematizá-la e, diante das diferentes possibilidades, elegerem aquele aspecto que consideram mais relevante para o estudo naquele momento, torna-se decisivo para o seu engajamento na continuidade do processo. Eles se sentem coresponsáveis pela construção do conhecimento acerca do problema e de alternativas para a sua superação, o que diminui a percepção de controle externo para a realização da atividade acadêmica e contribui para a constituição gradativa de sua autonomia.

- Nesse caminho, pelas características das etapas e pelo seu conjunto, pelas informações técnicas, científicas e empíricas que acessam e utilizam para a realização das atividades, os alunos vão sendo estimulados a confirmarem suas crenças, seus valores e seus conceitos anteriores, ou a colocá-los em dúvida, ou até reformulá-los, pelos novos aprendizados.

- Todo o processo desenvolvido permite tomar consciência da complexidade dos fenômenos sociais envolvidos no estudo.

- Pelas atividades que envolvem operações mentais de alto nível, como as de análise e síntese, por exemplo, e de todas as outras operações que ultrapassam a memorização, ocorre o estímulo ao desenvolvimento do pensamento crítico.

- O pensamento criativo dos alunos é estimulado, em cada etapa do processo.

- Os alunos são também mobilizados para aprendizados sociais, políticos e éticos, que contribuem para a formação do ser cidadão.

- Essas ações são orientadas metodologicamente pelo professor, que assume a condução e articulação cuidadosa do processo. Isso significa atuar como mediador e não como fornecedor de todas as informações ou autoria de todas as decisões.

- Associada a essa perspectiva de conduta pedagógica, estão as ações de acompanhamento, apoio e feedback constante do professor, tendo em vista alcançar os alvos da solução do problema eleito e consequente intervenção na parcela da realidade.

- A avaliação, nesse processo, portanto, é essencialmente formativa, também de processo, em que podem participar todos os envolvidos.

- Embora a estrutura permaneça constante, com as etapas do Arco, a sua aplicação é flexível, por adaptar-se às circunstâncias que cada grupo possui para estudar/investigar.

Em síntese, esta metodologia possibilita colocar em prática uma pedagogia problematizadora, pelo que é associada inegavelmente aos ensinamentos de Paulo Freire (BERBEL, 1999).

Todas as alternativas de metodologias ativas elencadas neste item colocam o aluno diante de problemas e/ou desafios que mobilizam o seu potencial intelectual, enquanto estuda para compreendê-los e ou superá-los. Os estudantes necessitam de informações, mas são especialmente estimulados a trabalhar com elas, elaborá-las e reelaborá-las em função do que precisam responder ou equacionar. Nesse caminho, é possível que ocorra, gradativamente, o desenvolvimento do espírito científico, do pensamento crítico, do pensamento reflexivo, de valores éticos, entre outras conquistas dessa natureza, por meio da educação, nos diferentes níveis, contribuindo para o desenvolvimento da autonomia na formação do ser humano e de futuros profissionais.

Em relação ao uso da metodologia da problematização com o Arco de Maguerez, alguns estudos foram realizados e apontaram para resultados interessantes em termos do 
desenvolvimento de alunos, em diferentes áreas. Entre os estudos disponíveis, a título de exemplo, mencionamos a pesquisa de Giannasi (1999), que buscou verificar a possibilidade de desenvolver habilidades de pensamento crítico, em um curso de educação continuada e a distância via Internet, para profissionais da informação, utilizando a metodologia da problematização. A autora elegeu, para isso, os níveis de pensamento crítico de Randy Garrison (1991 apud GIANNASI, 1999), as habilidades exigidas em cada nível, de James Henri e Ken Dillon (1992 apud GIANNASI, 1999), e desenvolveu um curso sobre Gerência de Sistemas de Informação, para profissionais dessa área, segundo as etapas da Metodologia da Problematização. Utilizou recursos existentes e disponíveis na Internet, tais como: e-mail, página de Web, lista de discussão e Web chat. As orientações aos alunos foram dadas na própria rede e em (pelo menos) um encontro presencial com a maioria deles.

A partir do planejamento e da execução do curso, Giannasi elaborou um instrumento de análise para avaliação do desenvolvimento do pensamento crítico demonstrado pelos alunos em cada etapa, com uma ementa para cada indicador e níveis de demonstração pelo aluno. Os alunos foram avaliados com o mesmo instrumento de análise no pré-teste e ao final do curso. Giannasi (1999) concluiu que nas condições do curso e modalidade de ensino utilizada foi possível desenvolver habilidades de raciocínio de ordem superior, tal como o pensamento crítico - Também o domínio de conteúdo aconteceu paralelamente. A autora sugere testar o instrumento de análise em outras situações de ensino, visando à validação do mesmo para o desenvolvimento do pensamento crítico em ambientes diferentes do utilizado na investigação.

Outra pesquisa, analítico-descritiva, com abordagem predominantemente qualitativa, foi desenvolvida por Prado Junior (2002) com um grupo de sete alunos do $3 \mathrm{O}$ ano do curso de graduação em arquitetura e urbanismo de um centro universitário de Londrina, em Estágio Supervisionado I, buscando verificar que resultados podem ser obtidos no desenvolvimento de pensamento crítico e criativo em alunos de Arquitetura e Urbanismo, quando estimulados através da metodologia da problematização. Prado Junior elaborou uma proposta de ensino, com objetivos para cada etapa, as estratégias e atividades de preparação e de aplicação, propostas para estimular o desenvolvimento do pensamento crítico e criativo nos alunos, e um instrumento com as escalas de avaliação das habilidades, suas ementas e níveis de demonstração. Utilizou essa escala para analisar um exercício preliminar, tendo como foco alguns problemas de arquitetura, visando a estabelecer uma referência inicial quanto ao grau de demonstração das habilidades em questão pelos alunos, e as confrontou com as avaliações subsequentes, após cada etapa do experimento, denominado de exercício orientado, a partir de uma situação real da prática do estágio.

Todo o processo foi registrado, descrito e analisado. Os dados encontrados revelaram que todos os alunos avançaram no desenvolvimento das habilidades de pensamento crítico e criativo eleitas e, em seus depoimentos, apesar das dificuldades iniciais, todos avaliaram positivamente a experiência, e salientaram a relevância para suas vidas acadêmica e profissional. Prado Junior (2002) concluiu que as estratégias e atividades aplicadas durante o trabalho foram adequadas e provocadoras do pensamento crítico e criativo e sugere que novos experimentos sistematizados se realizem, visando a ampliação da discussão dos resultados.

Tomando como referência o trabalho de Giannasi (1999), um exemplo de utilização da Metodologia da Problematização com o Arco de Maguerez no ensino, na área da saúde, é o descrito por Tacla (2002), no livro "Desenvolvendo o pensamento crítico no ensino de enfermagem." A autora conduziu o estudo de 19 estagiários de enfermagem pediátrica, tomando como foco a unidade de ensino "A dor da criança e do adolescente" hospitalizados. Pela avaliação dos resultados ao longo do tempo do 
estágio, Tacla (2002) concluiu que todos os alunos apresentaram avanços em todas as habilidades de pensamento crítico estimuladas. Mesmo havendo variações de aluno para aluno em cada habilidade e em cada etapa da metodologia da problematização, pôde afirmar que "todos avançaram no sentido da elaboração crítica do conteúdo da unidade, manifestando formas de pensamento mais complexas que as geralmente aprendidas" (TACLA, 2002, p. 172).

Um último exemplo de pesquisa, este realizado no âmbito da formação de professores, as autoras buscaram conhecer quais as possibilidades de utilização da metodologia da problematização em estágios acadêmicos do curso de pedagogia junto à realidade escolar. Em seu relato, Vasconcellos, Berbel e Oliveira (2009) contam que registraram todo o processo vivenciado de orientação $\mathrm{e}$ supervisão junto às alunas e analisaram os 24 relatórios de estágio elaborados pelas mesmas, na maioria, em duplas. Examinaram os resultados dessa utilização, buscando extrair lições do processo, enquanto buscaram atingir os objetivos do estágio para a formação das alunas. Um dos depoimentos de uma dupla é revelador do valor percebido na utilização da metodologia da problematização. As alunas manifestam a crença de que cada etapa da metodologia da problematização lhes possibilitou um crescimento intelectual importante. Valorizaram o fato de trabalharem coma realidade, como concreto, o que foi de grande valia. Afirmaram também que passaram a entender o que é uma pesquisa, uma investigação, acreditando que esta não deva ficar só no papel, e que ao levantar os problemas passaram a ter a clareza que deveriam retornar à realidade a fim de contribuir para a solução do problema (Relatório da dupla de estágio 15).

As autoras afirmam que a análise dos relatórios permitiu destacar como o processo vivenciado proporcionou uma experiência rica e produtiva de formação às alunas envolvidas e também às supervisoras, tendo em vista os objetivos do estágio, a realidade escolar e a formação para a pesquisa.
Entre as lições extraídas do trabalho desenvolvido na pesquisa, Vasconcellos, Berbel e Oliveira (2009) afirmam que o mesmo possibilitou, sem dúvida, o desenvolvimento de habilidades de pesquisa e do espírito científico e o exercício de reflexão crítica e de autonomia intelectual, aspectos relevantes na formação do professor-pesquisador. Confirmam sua convicção de que, para trabalhar com produção de conhecimento, é necessário a assunção de uma concepção de ensino mais ampla, que ultrapasse os limites da sala de aula e da aula em si, num compromisso que vai além dos limites impostos pela burocracia institucional. Constataram que, para trabalhar numa perspectiva não tradicional na área do ensino, investindo nele com pesquisa, além de ousar, arriscar e não temer possíveis fracassos é necessário, sobretudo, acreditar no potencial de metodologias inovadoras, como a metodologia da problematização, e confiar na efetividade da ação docente comprometida com o desenvolvimento e o crescimento do aluno.

Vasconcellos, Berbel e Oliveira (2009) confirmam sua convicção de que a metodologia da problematização é uma alternativa de contribuição efetiva para formar o professor-pesquisador, já que se apresenta com potencial promissor para o ensino e para a pesquisa, constituindo uma referência para a docência no ensino superior, para a área de didática e para os pesquisadores, em sua própria formação continuada. Alertam para a necessidade de se continuar a insistir no envolvimento dos alunos de graduação/futuros professores num ensino com pesquisa, dando oportunidades para que eles desenvolvam um espírito científico e crítico, conquistem uma autonomia frente ao conhecimento e, sobretudo, tornem-se educadores que possam assumir sua parcela de responsabilidade pelo tipo de mundo e de sociedade que projetam.

Se pensarmos na formação do futuro professor e em especial o da Escola Básica, o uso de Metodologias Ativas constituir-se-á em importante referência para sua atuação de modo construtivo junto a seus alunos, no mesmo sentido da promoção 
da sua motivação autônoma. Ou seja, quanto mais alternativas de atuação pedagógica o professor tiver experimentado/desenvolvido durante a sua formação inicial, melhores condições pessoais e profissionais disporá para atuar com seus alunos e no conjunto das atividades escolares.

Em nenhum dos exemplos de metodologias ativas aqui apresentados, a preocupação maior está na competição entre alunos ou nas notas como forma de controle externo, mas no tipo de aprendizado e no desenvolvimento dos alunos que se preparam para ser profissionais.

\section{Para finalizar...}

Assim como ocorre com a teoria, uma metodologia, por mais promissora que seja pelas suas características, por si só, não transforma o mundo ou a educação, nem mesmo consegue promover a motivação autônoma dos alunos. Recorremos a Sánchez Vázquez (1977, p. 206-207) para conferir a sua afirmação:

\begin{abstract}
A teoria em si [...] não transforma o mundo. Pode contribuir para sua transformação, mas para isso tem que sair de si mesma, e, em primeiro lugar, tem que ser assimilada pelos que vão ocasionar, com seus atos reais, efetivos, tal transformação. Entre a teoria e a atividade prática transformadora se insere um trabalho de educação das consciências [...] uma teoria só é prática na medida em que materializa, através de uma série de mediações o que antes só existia idealmente, como conhecimento da realidade ou antecipação ideal de sua transformação.
\end{abstract}

Para que as Metodologias Ativas possam causar um efeito na direção da intencionalidade pela qual são definidas ou eleitas, será necessário que os participantes do processo as assimilem, no sentido de compreendê-las, acreditem em seu potencial pedagógico e incluam uma boa dose de disponibilidade intelectual e afetiva (valorização) para trabalharem conforme a proposta, já que são muitas as condições do próprio professor, dos alunos e do cotidiano escolar que podem dificultar ou mesmo impedir esse intento.
O papel do professor, nessa perspectiva, ganha um status de relevância, ao mesmo tempo em que se lhe acrescentam responsabilidades quando comparadas a estilos de trabalho convencionais. De acordo com a literatura da área motivacional, é pouco provável que os estudantes, em situação escolar, envolvamse espontaneamente em todas as atividades de aprendizagem de modo autônomo, com grande interesse, alegria ou prazer, como afirmam Deci e Ryan (2000 apud GUIMARÃES, 2003). A interação com seus professores é uma das principais fontes para a melhoria da qualidade motivacional. A empatia com o professor facilita a identificação pessoal com aquilo que ele apresenta em sala de aula, possibilitando a valorização das atividades e conteúdos propostos e a internalização das exigências ou demandas externas. Neste último aspecto, os estudantes endossam ou passam a perceber como suas as demandas para a realização de um trabalho de qualidade, o que contribui para o fomento da motivação autônoma que é associada com processamento profundo das informações, criatividade, persistência, preferência por desafios, entre outros resultados positivos.

Uma só forma de trabalho pode não atingir a todos os alunos na conquista de níveis complexos de pensamento e de comprometimento em suas ações, como desejados, ao mesmo tempo e em curto tempo. Essa é a razão da necessidade de se buscar diferentes alternativas que contenham, em sua proposta, as condições de provocar atividades que estimulem o desenvolvimento de diferentes habilidades de pensamento dos alunos e possibilitem ao professor atuar naquelas situações que promovem a autonomia, substituindo, sempre que possível, as situações evidentemente controladoras.

Cabe ao professor, portanto, organizar-se, para obter o máximo de benefícios das Metodologias Ativas para a formação de seus alunos. Além disso, um desafio interessante é o dos registros dos modos como as experiências docentes e discentes são realizadas com essas metodologias e seus efeitos junto aos alunos, de modo a ampliar as reflexões e as evidências de seus benefícios pedagógicos. 


\section{Referências}

ABREU, M. C.; MASETTO, M. T. O professor universitário em aula: práticas e princípios teóricos. 5 . ed. São Paulo: MG Ed. Associados, 1985.

AUTONOMIA. In: MICHAELIS: Moderno dicionário da língua portuguesa. Disponível em: $<\mathrm{http} / / /$ michaelis. uol.com.br/moderno/portugues/index.php? lingua = portugues-portugues\&palavra $=$ autonomia $>$. Acesso em: 11 jan. 2010.

BASTOS, C. C. Metodologias ativas. 2006. Disponível em: $\quad<$ http://educacaoemedicina.blogspot.com. br/2006/02/metodologias-ativas.html>. Acesso em: 14 fev. 2010.

BERBEL, N. A. N. A metodologia da problematização e os ensinamentos de Paulo Freire: uma relação mais que perfeita. In: _. (Org.). Metodologia da problematização: fundamentos e aplicações. Londrina: Eduel, 1999. p. 1-28.

Metodologia da problematização e sua contribuição para o plano da práxis. Semina: Ciências Sociais e Humanas, Londrina, v. 7, p. 7-17, nov. 1996.

BORDENAVE, J. D.; PEREIRA, A. M. Estratégias de ensino-aprendizagem. 4. ed. Petrópolis: Vozes, 1982.

BRASIL. Presidência da República. Casa Civil. Subchefia para Assuntos Jurídicos. Lei $n^{\circ}$ 9.394, de 20 de dezembro de 1996. Estabelece as diretrizes e bases da educação nacional. Disponível em: <http://www3.dataprev.gov. br/SISLEX/paginas/42/1996/9394.htm>. Acesso em: 17 ago. 2009.

BZUNECK, J. A.; GUIMARÃES, S. E. R. A promoção da autonomia como estratégia motivacional na escola: uma análise teórica e empírica. In: BORUCHOVITCH, E.; BZUNECK, J. A.; GUIMARÃES, S. E. R.(Org.). Motivação para aprender: aplicações no contexto educativo. Petrópolis: Vozes, 2010. p. 43-70

COLOMBO, A. A.; BERBEL, N. A. N. A metodologia da problematização com o Arco de Maguerez e sua relação com os saberes de professores. Semina: Ciências Sociais e Humanas, Londrina, v. 28, n. 2, p. 121-146, jul./dez. 2007.

CONSELHO NACIONAL DE EDUCAÇÃO. Câmara de Educação Superior. Resolução CNE/CES 3/2001. Diário Oficial da União, Brasília, 9 de nov. de 2001. Seção 1, p. 37.

FREIRE, P. Pedagogia do oprimido. São Paulo: Paz e Terra, 1996.

GADOTTI, M. História das idéias pedagógicas. 8. ed. São Paulo: Ática, 2001.
GANDIN, D. Planejamento como prática educativa. São Paulo: Loyola, 1983.

GIANNASI, M. J. O profissional da informação diante dos desafios da sociedade atual: desenvolvimento de pensamento crítico em cursos de educação continuada e a distância via internet, através da metodologia da problematização. 1999. Tese (Doutorado em Ciência da Informação) - Programa de Pós-Graduação em Ciência da Informação, Universidade de Brasília, Brasília.

GIL, A. C. Metodologia do ensino superior. São Paulo: Atlas, 1990.

GUIMARÃES, S. E. R. Avaliação do estilo motivacional do professor: adaptação e validação de um instrumento. 2003. Tese (Doutorado em Educação) - Programa de Pós-Graduação em Educação, Universidade Estadual de Campinas, Campinas.

HERNÁNDEZ, F.; VENTURA, M. A organização do currículo por projetos de trabalho: o conhecimento é um caleidoscópio. 5. ed. Porto Alegre: Artes Médicas, 1998.

HOLANDA, A. B. Novo dicionário da língua portuguesa. 2. ed. Rio de Janeiro: Nova Fronteira, 1986.

MITRE, S. M.i; SIQUEIRA-BATISTA, R.; GIRARDIDE MENDONÇA, J. M.; MORAIS-PINTO, N. M.; MEIRELLES, C.A.B.; PINTO-PORTO, C.; MOREIRA, T.; HOFFMANN, L. M. Al. Metodologias ativas de ensino-aprendizagem na formação profissional em saúde: debates atuais. Ciência e Saúde Coletiva, Rio de Janeiro, v. 13, 2008. Disponível em: <http://www.redalyc.org/ redalyc/pdf/630/63009618.pdf>. Acesso em: 23 mar. 2009.

PRADO JUNIOR, I. Desenvolvimento do pensamento crítico e criativo no ensino de arquitetura e urbanismo através da metodologia da problematização. 2002. Dissertação (Mestrado em Educação) - Universidade Estadual de Londrina, Londrina.

REEVE, J. Why teachers adopt a controlling motivating style toward students and how they can become more autonomy supportive. Educational Psychologist, Hillsdale, v. 44, n. 3, p. 159-175, 2009.

SAKAI, M. H.; LIMA, G. Z. PBL: uma visão geral do método. Olho Mágico, Londrina, v. 2, n. 5/6, encarte especial, nov. 1996.

SÁNCHEZ VÁZQUEZ, A. Filosofia da práxis. 4. ed. Rio de Janeiro: Paz e Terra, 1977.

TACLA, M. T. G. M. Desenvolvendo o pensamento crítico no ensino de enfermagem. Goiânia: AB, 2002.

UNIVERSIDADE ESTADUAL DE LONDRINA. Centro de Ciências da Saúde. Colegiado do Curso de Medicina. Problem based learning. 2005. Disponível 
em: <http://www.uel.br/uel/pbl/geral.htm>. Acesso em: 18 nov. 2005.

VASCONCELLOS, M.M. M.; BERBEL, N. A. N.; OLIVEIRA, C. C. Formação de professores: o desafio de integrar estágio com ensino e pesquisa na graduação. Revista Brasileira de Estudos Pedagógicos, Brasília, v. 90, n. 226, p. 609-623, set./dez. 2009. 
